\title{
A Escola Nacional de Administração (França) e sua Evolução
}

PIERRE RACINE

Diretor da ENA

Tradução de Marcos Henrique Cortes

Fonte: La Revue Administrative, Ano 26, n. 152, mar./abr. 1973

A Escola Nacional de Administração foi criada por Decreto de 9 de outubro de 1945 do Governo Provisório da República Francesa, presidido pelo General De Gaulle. Esta importante decisão havia sido estudada e preparada com o maior cuidado pela Comissão provisória de reforma da administração, colocada junto ao Chefe do Governo e cujo animador foi Michel Debré, então Procurador-Geral do Conselho de Estado e Comissário da República em Angers.

No clima da Liberação, caracterizado pelo reexame das instituições e das mentalidades, essa medida se devia situar em um programa geral de renovação do Estado e da administração: o recrutamento e a formação dos funcionários constituiam uma peca-chave do mesmo mas não a única.
A fim de se compreender o alcance da reforma é preciso lembrar-se de que na França o Estado não havia, até então, tomado a seu cargo a formação direta de seus funcionários, incumbidos da administração geral do país e de sua representação no exterior. Sem dúvida a França adotava, bem antes da Segunda Guerra Mundial, para o recrutamento de seus funcionários, o sistema generalizado do concurso de ingresso nos diferentes órgãos ou ministérios. Mas o Estado não havia até então julgado necessário formar ele próprio, em escolas diretamente subordinadas a ele, seus funcionários em geral. Eram apenas formados em tais escolas - se excetuamos os Oficiais de carreira - os grandes corpos de engenheiros do Estado que, ao sair da Escola Politécnica, recebiam em escolas especiali- 
zadas, chamadas escolas de aplicação, a formação correspondente a seus setores: Engenheiros de Minas, de Pontes e Pavimentação, de Engenharia Marítima, de Engenharia Rural etc.

No campo da administração geral propriamente dita somente os futuros administradores da França Ultramarina eram formados em uma escola especial do Estado.

Ao contrário, os funcionários de natureza geral, destinados à administração interna ou à representação externa da França, eram recrutados por meio de concursos, abertos apenas para os alunos diplomados pelo ensino superior, de um nível igual pelo menos à licenciatura. Um grande número desses jovens recebiam sua instrução não só na Universidade, nas Faculdades de Direito e de Letras, mas em uma escola particular, criada logo após a guerra de 1870 , que havia conquistado justamente uma fama muito grande, a Escola Livre de Ciências Políticas. Essa Escola preparava diretamente uma parte de seus alunos para os concursos de acesso à função pública: Conselho de Estado, Tribunal de Contas, Inspetoria-Geral de Finanças, Corpo Diplomático e Consular, quadros de redatores dos principais Ministérios etc. Embora fosse particular e inteiramente livre em seu funcionamento, essa Escola tinha laços especiais com a administração : uma grande parte de seu corpo docente provinha, na realidade, de funções públicas e era a associação, dentro desse corpo docente, de altos funcionários, de universitários e de responsáveis por empresas do setor privado que haviam dado a seu ensino a reputação que ele merecia por sua abertura em relação ao mundo, sua percepção dos problemas concretos e da sintese.

$O$ regime de recrutamento e de formação anterior a 1945 se caracterizava por dois traços essenciais:

- diferentemente do regime britânico de recrutamento do "Civil Service" (Serviço Público Civil) por meio de um concurso único organizado por uma única autoridade, a "Civil Service Commission", cada órgão ou ministério francês realizava seu próprio concurso especial; assim ocorria no Conselho de Estado, na Inspetoria-Geral de. Finanças, no Tribunal de Contas, no Corpo Diplomático e Consular, em cada Ministério etc., enquanto que os quadros das prefeituras não eram recrutados na base através de concurso, mas segundo um sistema de requisição pura e simples por cada Prefeito;

- não existia escola do Estado alguma para prover a formação dos jovens que se destinavam ao serviço público, fora os grandes corpos de técnicos, do exército e do ultramar.

Esse regime deu à administração francesa gerações de jovens funcionários de um alto nível intelectual, possuindo já um certo sentido do serviço público, que resultava em grande parte do ensino ministrado por mestres que pertenciam à administração ou à diplomacia, mas em 1945 ele foi considerado ultrapassado sob vários pontos de vista. Na verdade se lhe fizeram quatro críticas principais: 
a) desigualdade e falta de homogeneidade dos diversos recrutamentos para a função pública superior. Os quadros de órgãos como o Conselho de Estado, a Inspetoria-Geral de Finanças, o Tribunal de Contas e o Corpo Diplomático eram recrutados por concursos qualificados de grandes concursos devido a seu nível. Os diferentes Ministérios recrutavam, cada um separadamente, seus próprios funcionários pelo concurso chamado de redator, cujo nivel era muito diferente conforme as administrações, sendo o concurso de redator do Ministério de Finanças de nível elevado;

b) excessiva parisianização das altas funções públicas francesas : sem que se possa ser taxativo nesse campo, deve-se reconhecer que esses concursos, especialmente os grandes, atraiam em especial os jovens oriundos de famílias parisienses, pela simples razão de que eram muito mal conhecidos nas províncias e que não havia nas universidades qualquer estímulo para preparação para os mesmos. Por outro lado, o ensino das $\mathrm{Fa}$ culdades de Direito e de Letras, qualquer que fosse sua qualidade, era inteiramente inadequado aos programas dos concursos, nos quais era impossível lograr aprovação sem vir a Paris;

c) origem social demasiado limitada da maioria dos candidatos. Esses concursos, abertos a jovens que tivessem ao menos colado grau ou possuissem um diploma equivalente, atraiam os jovens cujas famílias podiam arcar com o encargo financeiro de pelo menos três anos de estudos superiores, o que, na época em que o regime de bolsas e de facilidades financeiras não era tão amplo como hoje, limitava enormemente o leque social dos candidatos. Em segundo lugar, não se podendo passar nesses concursos senão após estar quite com as obrigações militares, os jovens já liberados delas tinham ainda que aguentar o ônus financeiro de um ou dois anos de preparação especial para o concurso por eles escolhido, preparação que era então feita na Escola de Ciências Políticas, em estreita ligação com representantes de cada órgão ou Ministério em questão.

Não obstante, o sistema de recrutamento tal como funcionava em razão dos princípios que regiam a função pública francesa colocava todos os candidatos que estavam habilitados a apresentar-se em um pé de estrita igualdade jurídica. Mas sendo esses concursos preparados sob a autoridade de mestres que pertenciam aos diferentes órgãos e ministérios, havia-se criticado o sistema como sendo um regime de requisição, não se devendo tomar esse termo num sentido pejorativo do ponto de vista de respeito pela igualdade dos candidatos, mas indicando que cada órgão era o único senhor de seu próprio recrutamento e sobretudo dos critérios de seleção, matéria evidentemente mais subjetiva e por vezes dificilmente controlável;

d) enfim, excessiva especialização dos diferentes concursos. Sem dúvida, especialmente nos grandes concursos, era necessário uma sólida cultura geral, ainda que ela não fosse averiguada através de provas especiais como o é hoje concursos de in- 
gresso na E.N.A., mas a maioria das provas, mesmo quando o programa era muito vasto, se concentrava nas disciplinas e problemas próprios dos diferentes órgãos ou ministérios, sendo entretanto exigidos sempre certos conhecimentos comuns em matéria de Direito, Economia e Finanças, embora em graus diferentes.

Assim, o concurso diplomático se concentrava essencialmente no conhecimento de línguas, de história diplomática e de geografia humana e econômica, enquanto que o concurso do Conselho de Estado tinha uma feição mais jurídica, embora extensiva muito amplamente a todos os setores da administração, e que o concurso da Inspetoria-Geral de Finanças ou do Tribunal de Contas se orientava de forma mais especial para problemas econômicos, financeiros, de matemática financeira etc. Todavia, o que caracterizava esses concursos era a preocupação de averiguar, através dos conhecimentos de base, a abertura de espírito, a inteligência em geral e, em certa medida, a personalidade do candidato.

\section{I - A ESCOLA NACIONAL DE ADMI- NISTRAÇÃO DE 1945 A 1972.}

\section{A Escola de 1945}

O decreto de 9 de outubro de 1945 marca uma mudança radical desses diferentes pontos de vista. Ela é dominada pelas seguintes idéias:

- a unidade de recrutamento e de formação dos futuros altos funcionários franceses em geral;
- a preocupação de diversificar social e geograficamente a origem dos candidatos;

- a importância atribuída, na formação dos candidatos recrutados, à experiência direta dos homens $\theta$ das coisas graças a um regime muito elaborado de estágios, parte integrante dos programas de escolaridade.

A fim de atingir esses objetivos e este é um outro traço fundamental do decreto de 1945 - é criada uma Escola Nacional de Administração (1), colocada sob a autoridade do Primeiro Ministro, isto é, ela não faz parte da Universidade. O Estado considera, a partir de entăo, que tem a responsabilidade não apenas de recrutar como também de formar seus próprios funcionários.

O desejo de abertura se manifesta no plano tanto social como geográfico.

No plano social duas medidas importantes contribuem para isso:

- Paralelamente ao concurso reservado aos estudantes, isto é, aos jovens cujas famílias terão podido, com ou sem bolsas, suportar o ônus de três ou quatro anos de estudos superiores, é criado um concurso especial, reservado aos jovens funcionários dos quais nenhum diploma é exigido. Sem dúvida certos candidatos dessa categoria puderam realizar estudos,

(1) Em 1848 havia sido criada uma primeira Escola de Administraçăo, que durou apenas 18 meses: ela recrutava categorlas de funcionários de niveis multo disparatados. 
até mesmo superiores, mas nenhuma exigência existe nesse âmbito e numerosos funcionários pertencentes aos quadros médios da administração podem apresentar-se a ele com possibilidades de êxito. Como esses jovens provêm de categorias sociais menos favorecidas, realiza-se por essa via, incontestavelmente, uma renovação social na alta função pública.

- Por outro lado, todos os alunos da Escola, uma vez aprovados no concurso, sendo considerados como funcionários-estagiários do Estado, mesmo se eram antes estudantes, recebem uma remuneração que lhes permite viver convenientemente, sozinhos ou com suas famílias se são casados. Não é mais necessário, para poder ingressar na alta função pública, após três ou quatro anos de universidade e o tempo de serviço militar, consagrar um ou dois anos à preparação de um concurso de recrutamento, como era o caso com o antigo sistema, em que a maioria dos jovens lograva aprovação entre 21 e 26 anos.

No plano geográfico, os autores da reforma de 1945, preocupados em diminuir a parte preponderante dos jovens de origem parisiense na administração superior, haviam decidido criar paralelamente ao Instituto de Estudos Políticos de Paris (novo nome dado à famosa Escola Livre de Ciências Políticas) um certo número de institutos de estudos políticos nas províncias, o primeiro dos quais foi instalado em Strasburgo a partir de 1945. Essa vontade de provincianização, se teve alguns efeitos nos primeiros anos de vida da nova escola, não conseguiu depois manter-se no ni- vel necessário por falta de medidas eficazes de auxílio dos estudantes provincianos e constitui um dos objetivos das reformas atualmente em andamento o de retomar esse esforço de uma forma mais vigorosa e mais coerente.

Quanto à natureza dos conhecimentos e à cultura exigidos nos concursos de ingresso, os autores da reforma, desejosos de reagir contra a especialização, julgada excessiva, dos antigos concursos, organizaram as novas provas sobre bases mais amplas abrangendo :

- uma sólida cultura geral composta sobretudo do conhecimento da evolução das sociedades a partir do século XVIII e de uma boa compreensão dos problemas do mundo contemporâneo nos campos político, econômico, social, cultural e técnico;

- sólidos conhecimentos de base nas matérias julgadas essenciais para a administração: Direito Público, Economia, legislação e questōes sociais, relações internacionais, finanças públicas, enfim conhecimento de uma língua estrangeira, que năo era anteriormente exigido exceto para ingresso no Qual d'Orsay *.

A primeira turma da E.N.A., que tomou o nome de "França Combatente" devido à ação que todos seus integrantes haviam realizado a serviço do país durante a guerra, ingressou na Escola em 1. de março de 1946. Esta turma, como duas outras da mesma

\footnotetext{
- Quai d'Orsay" é o Ministério das Relaçס̄es Exteriores da França (N. T.).
} 
origem, "Cruz de Lorena" e "Jean Moulin", beneficiou-se de um regime especial e foi, em especial, dispensada do estágio do $1 .^{\circ}$ ano em razão das provas de caráter que seus membros haviam dado durante a guerra e a resistência.

A primeira turma normal da Escola, que tomou o nome de União France$\mathrm{sa}$, ingressou alguns meses depois da "França Combatente", em 1. de junho de 1946. Desde então se seguiram, sem interrupção, 27 turmas.

O primeiro diretor da Escola, Sr. Henri Bourdeau de Fontenay, que não era funcionário antes da guerra de 1939-45, havia sido nomeado Comissário da República na Normandia pouco depois do desembarque de junho de 1944; ele conservou essas funções até março de 1946, data da supressão da administração excepcional dos Comissários da República e do retorno à administração municipal. Sob a direção do Sr. de Fontenay, a nova escola, mais feliz do que a de 1848 , assumiu rapidamente seu lugar na administração francesa, a despeito do ceticismo demonstrado por muitos quando de sua criação, sobretudo após a saída em janeiro de 1946 do General De Gaulle, chefe do Governo Provisório da República, que a havia criado.

Os princípios que formam a base da reforma de 1945 foram sempre firmemente mantidos : unidade de recrutamento para a alta função pública, exigência para o ingresso de uma boa cultura geral e de sólidos conhecimentos técnicos, formação em comum pela Escola, lotação dos alunos pelos diferentes órgãos e ministérios em função de sua classificação ao final do período letivo. Não obstante, a Escola teve ela própria três fórmulas de recrutamento e de formação.

A primeira fórmula, a de 1945 , fundava-se na busca de um cuidadoso equilíbrio tanto no recrutamento como na formação. O concurso de ingresso havia sido estruturado de maneira a levar a uma diversidade bastante grande da origem intelectual dos candidatos, pelo menos dos não científicos. De fato, embora fosse um concurso único para cada categoria, estudantes e funcionários, e comportando uma única classificação final, ele abrangia ao mesmo tempo:

- provas comuns de cultura geral, especialmente a primeira composição sobre a evolução das idéias e dos fatos políticos, econômicos e sociais a partir do início do século XVIII, e a entrevista com a banca com base em um texto;

- provas mais especializadas, correspondendo aos quatro ramos principais da administração, tal como eram vistos então, ou sejam, administração geral (jurídica e administrativa), econômica e financeira, social, e relações exteriores. Esses quatro ramos correspondiam aliás às quatro seções entre as quais eram repartidos os alunos uma vez admitidos na Escola. Desde o concurso de ingresso, as vagas abertas era, na realidade, repartidas entre as quatro seções. Os candidatos escolhiam livremente as matérias correspondentes à seção que preferiam, porém eram todos submetidos a uma classificação geral única, 
- que acarretava evidentemente cuidadosa avaliação relativa das provas que não eram comuns.

Este sistema podia ter como conseqüência que os candidatos declarados aprovados após essa classificação não obtivessem a seção de sua escoIha, mas então lhes era oferecido um dos lugares ainda livres nas seções que não estavam inteiramente lotadas. Eles podiam, aliás, recusar, demitir-se e se reapresentar no ano seguinte.

Durante anos esse regime permitiu 0 ingresso na Escola não apenas de jovens possuidores, em graus diversos, de sólidos conhecimentos de base utilizados na administração, Direito Público, Economia, Finanças Públicas, legislação e questões sociais, mas também, graças ao programa próprio à questão das relações exteriores, orientado essencialmente no sentido da história e da geografia humana e econômica, de candidatos de formação muito diferente: literatos puros, historiadores, filósofos, geógrafos, linguistas, que, uma vez ingressados na Escola, deviam adquirir os conhecimentos essenciais nos campos do $\mathrm{Di}$ reito e da Economia. Esses alunos que possuiam ao entrar uma formação profunda num campo determinado das ciências humanas, deviam sem dúvida se reconverter, mas a experiência demonstrou que a maioria o conseguia muito bem, precisamente em razão da qualidade de sua primeira formação.

Esse regime tinha, contudo, o inconveniente de tornar difícil o ingresso na Escola de jovens cuja formação de base era científica, pois eles não podiam, salvo exceções, adquirir em pouco tempo os ${ }_{4}$ conhecimentos em
Direito, Economia, História ou Geografia que possuiam os candidatos cuja primeira formação havia sido literária. Todavia, cada ano um aluno saído da Escola Politécnica com uma boa classificação podia requerer o ingresso sem concurso na Escola Nacional de Administração, em lugar de seguir o curso de uma das escolas de aplicação de $X$ e esta faculdade foi efetivamente utilizada, mas a contribuição dos setores científicos continuava simbólica.

Em segundo lugar, a própria formação dada à Escola, no regime primitivo, era igualmente muito equilibrada, pois repousava sobre uma sábia combinação de ensinamentos comuns a todos os alunos destinados a assegurar a unidade de espírito dos futuros funcionários e sua homogeneidade e, por outro lado, dos ensinamentos próprios de cada seção correspondente a um dos quatro ramos anteriormente indicados.

Eram comuns todos os estágios na administração e nas empresas, um certo número de cursos e, além disso, dos ensinamentos denominados interseções, relativos, para os alunos de cada seção, a conhecimentos essenciais pertinentes às três outras seções mas julgados necessários a qualquer funcionário, qualquer que fosse seu cargo.

Esses ensinamentos eram ministrados especialmente sob a forma de conferências sobre métodos, sendo que os alunos, sob a direção de um mestre de conferências geralmente tomado de empréstimo à administração, estudavam as matérias em pauta, 
sobre as quais recebiam treinamento fazendo composições, exposições ou quaisquer outros trabalhos correntes na administração, notas, relatórios etc.

Quanto às matérias próprias das seções, cada uma compreendia dois ensinos de base, ministrados segundo o mesmo método de conferências:

— seção de administração geral:

- matérias constitucionais, administrativas e jurídicas; ras;

- matérias econômicas e financei-

- seção econômica e financeira:

— matérias econômicas e financeiras;

- gerência de empresas;

- seção de administração social:

- legislação social;

- matérias sociais e econômicas;

- higiene, saúde pública, população, família;

— seção de relações exteriores :

- relações internacionais e Direito Internacional Público;

- Geografia Econômica; ras;

- matérias econômicas e financei-

- Direito Comercial e Direito Marítimo.

Esse ensino nas seções permitia uma formação aprofundada num campo essencial da vida pública, enquan- to que os ensinamentos comuns e interseções asseguravam a mesma abertura de espírito e a mesma faculdade de adaptação a todos os alunos, constituindo simultaneamente uma garantia de coesão da futura administração.

A reforma de 1945, cuidadosamente estudada e muito adaptada às necessidades reais da administração, produziu excelentes resultados. Ela foi, entretanto, modificada e mesmo abandonada em 1958 sob influência de uma corrente de idéias, das quais falaremos mais adiante, fato que só podemos lamentar hoje em dia.

No final do período letivo, a designação dos alunos pelas carreiras era feita segundo um sistema que, ao contrário, não pode hoje ser considerado como satisfatório e respondendo às necessidades das administrações.

Inicialmente, a despeito da existência das quatro seções, havia uma classificação geral única, tornada necessária por carreiras comuns, fosse nas quatro seções, fosse entre duas ou três delas. O Conselho de Estado, por exemplo, era comum às quatro seções, enquanto que a Inspetoria de Finanças e o Tribunal de Contas às três seçōes que não a de relações exteriores. A carreira de adido $\mathrm{co}^{-}$ mercial podia ser escolhida igualmente na seção de relações exteriores e na seção econômica e financeira. Mas a maioria das outras carreiras, e em especial a de administrador civil nos diferentes ministérios, eram repartidas de forma estrita entre as diversas seções. Por exemplo, os ministérios considerados da área econômica e financeira, e em primeiro lugar o $\mathrm{Mi}$ - 
nistério de Finanças, a Caixa de Depósitos e Consignações, os Ministérios de Indústria e Comércio, de Obras Públicas, da Agricultura, só podiam receber alunos oriundos da seção econômica e financeira, enquanto que de fato têm de lidar com um grande número de questōes de ordem jurídica, administrativa ou social. Os dois Ministérios da área social, do Trabalho e de Saúde Pública, só podiam receber alunos da seção social, enquanto que o Ministério da Educação Nacional só recebia os provenientes da seção de administração geral, e no entanto esses três ministérios teriam tido a maior necessidade de receber administradores dotados de sólida competência econômica e financeira, uma vez que se tornariam dois deles, Educação Nacional e Saúde Pública, os maiores investidores públicos da França, e que o terceiro, Trabalho, é responsável pela política de empregos, a qual depende intimamente da economia.

Os efeitos desse regime exclusivo de designação foram consideravelmento agravados pela aplicação lamentável feita, após a entrada em vigor do novo Estatuto Geral da Função Pública de 1946, da noção de "estatuto especial", em lugar do corpo único de administradores civis, um dos objetivos essenciais da reforma de 1945. Foram criados 23 quadros especiais de administradores, próprios de cada ministério ou mesmo mais de um para um único ministério, provocando no seio da administração central uma compartimentação $\theta$ uma disparidade de estrutura das quais ainda sofremos profundamente. Portanto, a partir de 1946 a idéia de uma política de con- junto foi quebrada, se não abandonada, em favor de uma volta à especialização de quadros, sem que a Escola pudesse fazer qualquer coisa contra esse movimento.

É preciso, entretanto, reconhecer que os efeitos desse regime de designações só se revelaram plenamente mais tarde e que, tal como havia sido cuidadosamente pensado na época da Liberação e aplicado de 1945 a 1958 , o primeiro regime de recrutamento e de formação da Escola era equilibrado e coerente, que ele proporcionou a todas as administrações, especialmente aos Ministérios da área social, funcionários dotados de grande abertura de espírito e de sólida competência nos principais campos de atividade do Estado, e que era plenamente satisfatório, reserva feita do que acabou de ser dito sobre a natureza demasiado rígida da designação dos alunos de cada seção.

\section{A Escola Nacional de Administração de 1958}

Em 1958, porém, esse regime foi profundamente modificado, sob a influência de vários fatores muito diferentes, especialmente defesa da idéia de funcionários "polivalentes", desejo do Ministério das Relações Exteriores de não limitar seu recrutamento aos alunos da seção de relações exteriores, desejo esse partilhado por outros ministérios que queriam receber jovens administradores mais diversificados do que os de uma seção. Mas em lugar de se se contentar com tornar mais flexível o que o regime de 1945 tinha de demasiado rígido na designação para as carreiras e de introduzir no ensino a modernização que 
começava a tornar necessário o desenvolvimento de modernos métodos de direção, criou-se em substituição um regime totalmente diferente.

Pelo decreto de 30 de dezembro de 1958 foi adotado um novo regime, que funcionou até maio de 1972, época em que a última turma da Escola submetida inteiramente a esse regime ingressou nas diferentes repartições.

Segundo essa concepção, todos os futuros altos funcionários deviam ser recrutados, no vestibular, com uma cultura e um grau de conhecimentos idênticos e formados na Escola dessa mesma maneira, colocando em pé de igualdade todas as matérias essenciais: Economia, Administraçã̃o e $\mathrm{Di}$ reito, questões sociais e relações internacionais.

Esse regime, organizado pelo decreto de 30 de dezembro de 1958, ele próprio objeto de modificações, das quais a mais importante decorria do decreto n. 65.946, de 24 de novembro de 1965, referente a regulamento de administração pública sobre as condições de acesso à E.N.A. e sobre período letivo, foi aplicado até a entrada em vigor do decreto $n .^{\circ} 71.787$, de 21 de setembro de 1971, o qual restabeleceu um regime de formação simultaneamente comum e diferenciada, como em 1945, porém sobre bases novas.

No regime de 1958, portanto, os concursos de ingresso eram uniformes.
Haviam sido conservadas as duas provas de cultura geral, instituídas em 1945, isto é, uma composição escrita sobre um tema relativo à evolução geral das idéias e dos fatos políticos a partir do meio do século XVIIII (2) e uma entrevista de $30 \mathrm{mi}$ nutos, com base em um texto de natureza geral.

Mas os conhecimentos técnicos bá. sicos considerados necessários eram os mesmos para todos. Os estudantes candidatos ao concurso tinham provas escritas e orais sobre as seguintes matérias :

- composição sobre economia;

- composição sobre um tema relativ̀o às instituições políticas e administrativas, bem como sobre as instituições internacionais; ciais;

- exame oral sobre questões so-

- exame oral sobre Direito Administrativo ou Finanças públicas, à escolha do candidato.

Além disso, na parte escrita, os estudantes candidatos tinham de fazer a tradução de um texto em idioma estrangeiro.

Quanto aos funcionários, mesmo se algumas provas eram simplificadas em seu conteúdo ou em seu programa, eram examinados nas mesmas bases, muito próximas das adotadas no concurso para estudantes. As maté rias básicas eram as seguintes:

(2) Para os funcionários candidatos a mesma prova cobria problemas políticos, econômicos e sociais do mundo contemporâneo. 
1) uma composição sobre as instituições políticas e administrativas, mas redigida com o auxílio de documentos fornecidos aos candidatos;

2) uma composição sobre economia e finanças públicas, igualmente com auxílio de documentos;

3) exames orais relativos a questões sociais e questões internacionais, não havendo prova especial alguma de Direito Administrativo ou de finanças públicas para esses candidatos que provinham da administração.

Quanto ao exame de línguas, para os candidatos funcionários só era feito nas provas de admissão, como para os estudantes, e compreendia igualmente a tradução de um texto escrito em idioma estrangeiro.

Diferentemente, portanto, do regime felizmente diversificado de 1945 , os concursos de ingresso do regime de 1964 conduziam à Escola candidatos de formação sem dúvida muito homogênea porém praticamente todos do mesmo modelo. A única flexibilidade introduzida, aliás de maneira muito limitada, residia na possibilidade de se obter pontos suplementares através de um certo número de opções diversificadas, sobretudo as matérias científicas, matemáticas e estatístiCas, além de uma segunda língua estrangeira ou outras matérias especificadas numa relação elaborada pelo Ministério encarregado da função pública. Entretanto, o efeito prático dessas opções era muito reduzido uma vez que só eram tomados em conta os pontos obtidos acima da média, isto é, de 10 .
Quanto à formação, baseada igualmente sobre a idéia de polivalência e de identidade dos alunos, abrangia ela, além dos estágios na administração das províncias ou em embaixadas e nas empresas industriais, comerciais ou bancárias, privadas ou públicas, que haviam sofrido poucas modificações, ensinamentos comuns a todos os alunos, com a única reserva da faculdade, de alcance muito limitado, de substituir o estudo de uma segunda língua estrangeira pelo de uma matéria optativa, freqüentemente escolhida dentre as matérias cientificas ou de técnica gerencial.

$\mathrm{Na}$ realidade as quatro seções de 1945 haviam sido suprimidas e os estudos compreendiam agora as seguintes matérias, uniformes para todos:

1.) Quatro matérias chamadas básicas, postas em um mesmo nível: assuntos administrativos e jurídicos, assuntos econômicos e financeiros, assuntos sociais, relações internacionais.

2.') Dois idiomas estrangeiros, dos quais o segundo podia ser substituído por uma opção relativa às matérias oferecidas aos alunos, a maioria desenvolvendo os ensinamentos de iniciação à gerência moderna ou referente a matemática, estatísticas, Direito em profundidade etc.

Originariamente 0 programa das quatro matérias básicas era sensivelmente a soma do programa das quatro seções anteriores. Caso esse programa tivesse sido aplicado inteiramente, teria exigido um esforço gigantesco dos alunos e dos mestres de conferências. Assim sendo $-\mathrm{e}$ este foi 
um dos principais objetivos do decreto de 24 de novembro de 1965 - a direção da Escola tinha a liberdade de escolher, no âmbito de cada matéria básica, um ou vários temas que eram estudados pelos alunos de forma mais profunda, especialmente através de seminários, funcionando paralelamente à tradicional conferência de método.

Quanto à pedagogia mesma da Escola, no curso desse período ela evoluiu progressivamente. A conferência de método, muito ligada aliás à noção mesma de programa extenso e compreendendo exercícios escolares do tipo de exposição oral e composição escrita, algumas das quais sobre dossiers, foi progressivamente desaparecendo para ser substituida pelo método do seminário, no qual os alunos são iniciados no trabalho em grupo, estudam apenas problemas reais e realizam grandes pesquisas fora da Escola, nas administrações, empresas ou sindicatos, a fim de formar uma opinião e propor soluções aplicáveis.

Paralelamente, e sobretudo a partir de 1968 , foi feito um esforço grande pela iniciação dos alunos nas técnicas modernas de gerência, em matemáticas e estatística, contabilidade de empresas, informática etc., esforço necessário mais difícil na medida em que a enorme maioria dos alunos da Escola é composta de jovens que têm uma formação predominantemente literária e possuem bons conhecimentos de direito, economia geral, questões sociais e internacionais, mas nenhuma formação científica. Apenas um pequeno número deles possuiam tal cultura ao ingressar, embora nos últimos anos sua proporção tenha aumentado, sem ultrapassar de 12 a $15 \%$.

O regime de 1958-65 teve certamente como resultado fazer entrar na Escola, e mais tarde na função pública superior, jovens possuidores de uma boa cultura geral, uma ampla abertura de espírito sobre todos os problemas $e$, em conseqüência, uma grande capacidade de adaptação, qualidades eminentemente preciosas hoje, quando o Estado precisa conduzir uma sociedade em plena mutação.

Esse regime apresentava, contudo, sérios inconvenientes, tanto sob 0 ponto de vista dos alunos como das administrações e esses inconvenientes se evidenciaram ano após ano.

A necessidade de estudar todas as matérias em pé de igualdade era de molde a criar uma tensão intelectual excessiva nos alunos e a se constituir num obstáculo a qualquer exame em profundidade das matérias. Esse aspecto é particularmente evidente em Economia, na qual os administradores não poderiam se contentar hoje com conhecimentos muito gerais. Mesmo que os alunos saídos da Escola năo devam ser especialistas, nem mesmo economistas no sentido estrito do termo, e menos ainda econometristas, mas sim administradores aptos a servir nas diversas administraçōes, um certo número deles tem necessidade de possuir uma formação econômica mais alentada e moderna, isto é, que suponha conhecimentos científicos suficientes. Todos os outros devem ter sólidos conhecimentos econômicos a fim de serem capazes de pensar so. bre sua atuação em termos econômi- 
cos e devem igualmente ser iniciados na gerência moderna. O regime de polivalência serviu assim de obstáculo durante anos à definição do que deve ser, num Estado ocidental moderno, um administrador economista e à elaboração da pedagogia necessária para tal efeito.

Essas dificuldades foram tanto mais sentidas quanto o regime de repartição dos alunos entre as carreiras estava baseado numa classificação final de saída, classificação esta agora rigorosamente única para todas as administraçōes, diferentemente do que ocorria em 1945. O desafio dessa classificação tornou-se uma parcela excessiva das preocupações dos alunos, que estabeleceram entre os diferentes órgãos e ministérios uma hierarquia quase sistemática, coonestada aliás pela sociologia administrativa, isto é, o estado de espírito e os costumes da administração. Os alunos oriundos do concurso de "funcionários", que trazem ao Estado uma validade e uma noção de serviço preciosas, se viam particularmente prejudicados em relação a seus colegas "estudantes", cujo passado universitário tornava mais aptos para se adaptar a esse regime intelectual.

Ao mesmo tempo resultou daí que certas administrações, antes, no regime das seções, abastecidas sem dificuldade de jovens administradores, passaram a ter problemas para recrutá-los e simultaneamente a ser consideradas de maneira desfavorável pelos alunos que saíam da Escola. Esse fenômeno era ainda mais lamentável por serem essas administrações as que têm um papel capital na evolução da Nação: Ministérios de Educação
Nacional, Saúde Pública, Trabalho etc. $\mathrm{Na}$ verdade, um regime uniforme de recrutamento e de formação não estimula as vocações, quando mesmo não as desencoraja.

Em 1968 o Governo incumbiu uma Comissão presidida pelo Sr. François Bloch-Lainé, Inspetor-Geral de Finanças e Presidente do "Crédit Lyonnais", de estudar a reforma da E.N.A. O relatório dessa Comissão foi entregue ao Governo no fim da primavera de 1969. Após ter feito o histórico da vida da Escola e a análise dos problemas que sua existência apresentava não só para si mesma como para a administração, a Comissão concluiu pela manutenção de uma Escola Nacional de Administração, escola ao mesmo tempo de recrutamento e de formação, segundo o modelo adotado em 1945. Mas no que se refere à formação, uma de suas recomendações mais importantes foi a do abandono do regime de polivalência.

A Comissão assim se expressara, e seu pensamento merece ser reproduzido aqui : "A pretensão atual do enciclopedismo é um logro e prejudica a qualidade da formação. Mesmo com uma sólida formação superior no começo, não se pode adquirir na E.N.A. as competências suficientes para se tornar simultaneamente um economista completo, um publicista informado, um especialista em assuntos sociais ou internacionais".

A Comissão acrescentava que o perfil desejável do antigo aluno da E.N.A. parecia ser o de um generalista, mas valorizado pelo domínio de duas ou três técnicas, não se enten- 
dendo essa palavra em um sentido estreito. Ela concluia por sua preferência por uma formação diferenciada. Contudo o relatório, embora contivesse preciosas indicações gerais, não havia proposto qualquer regime elaborado de recrutamento e de formação.

E este foi o tema dos estudos feitos pela nova direção, em intima ligação com a Diretoria Geral da Função Pública, que levaram ao decreto de 21 de setembro de 1971, ou seja, a definição desse novo regime.

O relatório da Comissão de reforma continha, por outro lado, sugestões muito importantes sobre a reforma da própria administração, partindo da idéia, óbvia e infelizmente esquecida, de que os reformadores de 1945 estavam intimamente convencidos, de que se a Escola é feita para a administração e suas necessidades, Escola e administração devem ser coerentes entre si.

Em primeiro lugar, as necessidades de todas as administrações têm de ser atendidas, tanto quantitativa como qualitativamente, o que é tanto mais verdade quanto a penúria de quadros de numerosos ministérios franceses foi camuflada de forma provisória durante anos pela incorporação maciça de funcionários de qualidade que haviam perdido sua razão de ser no ultramar em decorrência da política de descolonização.

Por outro lado, quando se recruta e forma juntos, com tanto cuidado, os futuros administradores, estes têm o legítimo desejo de servir de maneira útil, de se ver confiar atividades interessantes e, rapidamente, responsabilidades, qualquer que seja a ad- ministração para a qual foram designados à vista de sua classificação. $O$ interesse das administrações e do país vai no mesmo sentido. Por conseguinte, a diversidade das funções, que é evidente e aliás plenamente conforme com a realidade da administração, deve ser acompanhada de uma política de bom emprego de todos esses jovens funcionários e de uma certa harmonização, mas não de uma identidade impossível, de suas carreiras, pelo menos durante os oito a dez primeiros anos. Em seguida a vida, a diversidade de talentos e as circunstâncias criarão diferenças muito naturais.

No quadro dessas preocupações a Comissão tinha sido levada a propor, especialmente no âmbito das carreiras, uma série de ajustes destinados a manter no conjunto do corpo de funcionários egressos da E.N.A. o sentimento de unidade que lhes deve dar a Escola.

Realmente é um fato que, se os alunos preferem em suas escolhas os mesmos órgãos e os mesmos ministérios, o que ocorreu até maio de 1972, quando o Conselho de Estado, a Inspetoria de Finanças, o Tribunal de Contas, depois os Ministérios de Economia e de Finanças e a carreira para Prefeito eram considerados como os únicos destinos interessantes, 0 clima se deteriora não só numa escola em que a classificação tem tal papel, mas no conjunto das administrações, e especialmente naquelas que se consideram desprestigiadas. Este é um dos problemas mais importantes que se colocam hoje, como o tinham ressaltado os autores da 
reforma de 1945 no comentário publicado sob a autoridade da Presidência do Governo a respeito da reforma da função pública, reforma que compreendia :

- o ensino de ciências políticas;

- a criação da Escola Nacional de Administração;

- a reforma das administrações;

- uma política da função pública e a criação de uma direção da função pública.

Sua opinião merece ser recordada, realmente, pois ela tem mais atualidade do que nunca:

A reforma levando à criação da Escola Nacional de Administração "mesmo continuando a ser uma questão de ensino, é para falar a verdade uma reforma administrativa".

E, mais adiante, é preciso "por um lado tentar obter, sempre mantendo algumas diferenças que serão justificadas, uma similitude tão grande quanto possível entre o estatuto e a carreira dos funcionários egressos da Escola nos distintos serviços. Por outro lado, ordenar que, ao longo de suas carreiras, os funcionários de uma determinada administração tenham passado por uma outra administração ou por um serviço no exterior, a fim de aumentar sua experiência e de manter a unidades de vistas. Porém essas duas conseqüências ultrapassam o quadro das administrações ligadas à Escola Nacional de Administração. Elas fazem parte já da reforma administrutiva".
A reforma administrativa é uma das responsabilidades do Governo como um todo e falaremos dela mais adiante. Porém, no âmbito deste artigo, os desenvolvimentos que se seguem só se referem à própria Escola, isto é, seu recrutamento, a formação que ela proporciona e seu regime interno, tais como são agora estabelecidos pelo decreto de 21 de setembro de 1971. Junto com a reforma da Escola efetuada por esse texto, o Governo decidiu ademais adotar um certo número de medidas relativas às carreiras e ao emprego dos funcionários formados pela E.N.A., medidas publicadas em 1972, que são apenas o modesto início de uma política de conjunto.

II - REFORMA DA ESCOLA NACIO. NAL DE ADMINISTRAÇÃO DE 1971.

IDÉIAS BASICAS DA REFORMA DE 1971.

Diversidade do recrutamento sob o ponto de vista tríplice intelectual, geográfico e social.

Não é bom que a Escola e a administração só recebam alunos e funcionários de um modelo único, oriundos quase todos da formação dos Institutos de estudos políticos e da colação de grau em Direito Público.

Retomando e atualizando as preocupações de 1945, a reforma prevê também medidas tendentes inicialmente à diversificação geográfica e social do recrutamento pelos estímulos que serão dados aos estudantes das províncias, os quais praticamente 
não podem hoje esperar ingressar na Escola sem vir a Paris estudar no Instituto de estudos políticos. Serão celebrados para tal fim convênios entre a E.N.A. e os Institutos ou Centros de preparação e uma ajuda intelectual e material será concedida aos melhores estudantes desses organismos. Esses convênios de ajuda e cooperação se referem essencialmente às províncias, uma vez que seu objetivo principal é o de incentivar a preparação dos centros provinciais, mas, como essas medidas encerram ao mesmo tempo um aspecto social, podem igualmente delas se beneficiar estudantes parisienses do Instituto de estudos políticos e das universidades. Este novo regime só se aplica aos estudantes, pois os jovens funcionários já se beneficiam do regime de facilidades de preparação, que a reforma melhorou ainda mais. Os primeiros convênios foram celebrados, a partir de 1972, com cinco centros provinciais e dois parisienses.

A mesma preocupação de diversificação é encontrada no plano intelectual, porém dentro dos limites necessários à manutenção da unidade da Escola. É a essa preocupação que responde a criação, tanto para os estudantes como para os funcionários, de dois concursos. Esse novo regime tem por base três idéias :

- os concursos devem continuar a ser concursos em que os candidatos devem fazer prova de uma sólida cultura geral e os exames correspondentes são portanto mantidos com certas modificações : composição geral sobre os problemas políticos, econômicos, sociais, culturais, internacionais do mundo contemporâneo e entrevista com a banca;

- mas, ao mesmo tempo, esses concursos devem permitir averiguar a existência de uma formação verdadeira em um dos dois campos básicos da administração, o Direito Público, no sentido lato do termo, e a Economia. Eles devem também permitir aquilatar, ao lado do espírito de síntese, que o concurso atual apura bem através de certas provas, a capacidade de análise de raciocínio rigoroso dos candidatos, o que não ocorre atualmente.

Como há duas formações básicas na administração, dois concursos são estabelecidos para cada categoria, de estudantes e de funcionários, num predominando o Direito Público e noutro a Economia. Mas como essa dualidade não deve constituir obstáculo à amalgação dos alunos e à unidade da administração, o novo texto prevê que cada concurso deve abranger a averiguação dos conhecimentos bási$\cos$ do campo do outro concurso; os candidatos ao concurso em que predomina o Direito Público terão assim uma prova de Economia, da mesma forma que os candidatos ao concurso em que predomina a Economia serão examinados sobre Direito Público, sendo essas provas naturalmente menos difíceis para esses candidatos do que para os que optarem pela outra matéria principal.

- provas de conhecimentos técnicos que permitem, finalmente, averiguar o nível dos candidatos em campos essenciais, matérias sociais, internacionais, finanças públicas, um 
idioma estrangeiro, mas com pequenas variações conforme cada tipo de concurso.

Por fim, uma última idéia foi adotada, segundo a qual os candidatos devem, além das matérias obrigatórias, apresentar uma opção que lhes permita demonstrar cultura pessoal ou uma certa formação em campos variados, História e Geografia, ciências humanas, matérias científicas, e técnicas modernas de gerência.

O concurso para funcionários foi alvo de um cuidado especial : pareceu necessário não só mantê-lo mas também melhorá-lo, pois esse recrutamento é de grande interesse para a função pública, tanto sob o ponto de vista de abertura social como de solidez da administração.

O texto prevê inicialmente que se poderia de novo aumentar a proporção dos alunos dessa origem, limitada a um terço em 1958, contrariamente à prática estabelecida em 1945, que lhe reservava a metade das vagas.

Em seguida, melhorou-se muito o regime das facilidades de preparação, em virtude do qual os jovens funcionários são previamente selecionados através de provas de ordem geral e se beneficiam então, sem ter de prestar qualquer serviço ao Estado, de estudos e de exercícios criados especialmente para seu proveito, para colocá-los no nível de conhecimentos e de cultura dos estudantes.

Dentro desse espírito, far-se-á uma melhor pré-seleção, fundada na distinção entre os funcionários que possuem diplomas de ensino superior e os que não os têm. O regime de concurso prévio, isto é, das provas de pré-seleção, assim como a duração das facilidades de preparação, serão adaptados em função dessa distinção e especialmente alongados, pois podem atingir mesmo três anos. Em sentido inverso, a reforma que cria dois concursos para os estudantes é estendida aos funcionários a fim de que o concurso desses últimos seja considerado como contendo as mesmas exigências e o mesmo nível.

\section{0 regime de formação}

O novo regime se assenta, em primeiro lugar, sobre o abandono da idéia falsa da polivalência, não consistindo a verdadeira polivalência na dos programas e das matérias impostas uniformemente a todos os alunos, mas a aptidão de se aperceber de todos os aspectos de um problema, o que poderíamos chamar de polivalência dos pontos de vista. Todo problema comporta, na realidade, aspectos administrativos e jurídicos, econômi$\cos$ e financeiros, sociais e psicológicos, freqüentemente internacionais; é para essa abertura que se precisa treinar os alunos e não fazê-los a todos percorrer os mesmos programas $\theta$ as mesmas matérias.

A dualidade dos concursos, bem como a criação no seio da Escola de duas vias de formação diferenciada e de opções, tende para esse objetivo. A nova Escola repousará portanto nas seguintes bases:

- uma formação equilibrada entre uma formação comum a todos e uma diferenciação razoável; 
- um melhor equilibrio e, sobretudo, uma melhor ligação entre os estágios e os estudos;

- uma pedagogia fundada na idéia de que a Escola é uma escola de aplicação, o que comporta igualmente bem os ensinamentos de gerência moderna e os métodos de formação muito próximos da realidade administrativa: trabalhos de grupo, seminários, discussão de casos concretos, estudo de problemas reais, trabalho administrativo durante parte do tempo, sem prejuízo dos estágios na administração local e regional e nas empresas.

Não obstante, não se cogitou de reverter ao regime das seções, porque não se pode ressuscitar uma instituição, ainda que boa, que desapareceu, e o projeto de reforma prevê apenas a criação de duas vias de formação e de classificação diferenciadas, a via da administração geral e a via da administração econômica, completadas por um certo número de opções que permitirão aos alunos, cada um segundo seus gostos e as necessidades da administração, adquirir um começo de especialização nos diferentes campos.

Dentre essas opções uma tem uma feição especial, a opção internacional, no sentido de que é a única para a qual está previsto um vínculo entre a própria opção e a escolha de uma carreira, a saber as carreiras exteriores. Daqui por diante um aluno não poderá ingressar no Ministério das Relações Exteriores e no Corpo da Expansão Econômica se não tiver feito essa opção e sido aprovado nos exames correspondentes. $\mathrm{Na}$ verdade não se quis criar uma nova via inter- nacional, colocada no mesmo nível da via da administração geral e da via da administração econômica, por diversas razões. Temeu-se sobretudo que essa via se tornasse uma via estreita, fechada sobre si mesma, enquanto que os diplomatas modernos devem estar informados sobre todos os problemas de uma sociedade e de um Estado, ter contatos com todos os círculos, estar aptos a tratar de problemas econômicos e sociais e até mesmo incumbir-se de uma certa administração de pessoal e de créditos orçamentários no quadro de acordos de cooperação.

A escolha pelos alunos das vias de formação e das opções é feita nas seguintes condiçöes :

Excetuado o regime transitório dos primeiros anos para os alunos que haviam passado nos antigos concursos e que têm uma total liberdade de escolher sua via, o novo regime estabeleceu uma correspondência entre 0 concurso feito e a via. Assim um aluno, estudante ou funcionário, que foi aprovado no concurso dito de predominância de Direito Público, deve, em princípio, seguir a via da administração geral, enquanto que o que passou pelas provas do concurso de predominância econômica deverá escolher a via da administração econômica. A formação é, na realidade, um todo $e$ há todo interesse em valorizar sua formação de base, uma vez que os alunos terão, em decorrência de certas provas dos concursos e de sua formação, sólidos conhecimentos comuns. Ainda que se o tenha pensado, deixou-se de fazer na Escola um "recobrimento cruzado" sistemático, que 
teria aliás terminado por recriar, sob uma outra forma, uma polivalência que se havia condenado.

Contudo, a fim de ter em conta o desejo que podem ter alguns alunos de mudar de orientação, uma vez na Escola o novo regime autoriza a passagem de uma via para outra até $5 \%$ na entrada e, posteriormente, por meio de permutação.

Essas medidas permitem uma flexibilidade suficiente, ressaltando-se que à medida em que for sendo aplicado o regime, a via da administração econômica, cujo nível científico, na entrada, é o do ensino em matemáticas e em estatísticas dos três primeiros anos da licenciatura em ciências econômicas, dificilmente seria seguida pelos alunos de formação puramente literária, que colaram grau ern Direito Público ou passaram por um Instituto de estudos políticos. De toda maneira, ela só o seria ao preço de um esforço muito grande de reconversão, que a Escola aliás facilitará por meio de ensino intensivo de recuperação para os que estiverem decididos a fazê-lo.

Em sentido contrário, as opções são feitas pelos alunos com uma liberdade total, sem qualquer referência aos concursos de ingresso.

\section{Regime de designação e de classificação}

Este regime é profundamente diferente, não só do de 1958 como também do de 1945 !
Ele se assenta na idéia de que todas as administrações têm necessidade de receber funcionários de formação sem dúvida homogênea, porém diferenciada. É certo que, como já se disse, os ministérios da área social de natureza mais nitidamente administrativa têm necessidade de administradores predominantemente econômicos; da mesma forma, os ministérios da área econômica e principalmente os Ministérios da Economia e de Finanças, empregam um número muito alto de administradores predominantemente jurídico-administrativos ou sociais, ainda que todos devam ter uma formação econômica e mostrar-se capazes de raciocinar em termos econômicos.

Um órgão como o Conselho de Estado, que passa por ser essencialmente jurídico, tem igualmente vantagens em receber jovens com formação eco. nômica, pois que é chamado, tanto em suas seções administrativas como no contencioso, a se ocupar de questões as mais variadas, algumas das quais têm um evidente caráter econômico, mesmo fora das questões tributárias.

Nessas condições, daqui por diante todos os órgãos e administrações re. ceberam, todo ano, alunos provenientes das duas vias, numa proporção variável, respondendo a suas próprias exigências, estabelecida pelo Primeiro Ministro mediante proposta do Minis tro encarregado da função pública.

A distinção dessas duas categorias de administradores vai tornar necessária, para cada administração, uma análise mais rigorosa e mais fina de 
suas necessidades e uma pesquisa está atualmente sendo feita a esse respeito.

Anualmente, portanto, e antes mesmo que os alunos escolham suas vias, os diferentes postos que lhes serão oferecidos ao saírem da Escola são distribuídos entre as duas vias nas condições que acabam de ser indica. das, mas também de uma forma equilibrada a fim de que nenhuma das vias seja privilegiada em suas oportunidades.

O novo regime das vias tem por conseqüência a substituição da classificação única do sistema de 1958 por duas classificações finais, inteiramente distintas, uma para cada via.

Quanto à opção internacional, cuja adoção é necessária para se poder pretender escolher uma das carreiras exteriores (carreira diplomática ou consular e corpo de expansão econômica), o jogo é o seguinte:

Os alunos a escolhem livremente, como toda opção. Mas se desejam poder conseguir, ao saírem e se sua classificação o permite, uma das carreiras exteriores (carreira diplomática e consular, corpo de expansão econômica no estrangeiro), têm de adotá-la e passar por suas provas.

Contudo a escolha dessa opção não obriga de forma alguma um aluno a entrar em uma dessas carreiras se, ao concluir o curso, ele deseja escoIher uma outra e se está, em função de sua classificação, em condições de fazê-lo. A opção internacional tem portanto como objetivo o de estimular as vocações exteriores sem obrigar a elas.

\section{A administração da Escola}

Um dos objetivos da reforma de 1971 consiste em adaptar a administração da Escola às exigências de hoje. Em primeiro lugar assegurando a participação real dos representantes dos alunos em todos os organismos de direção da Escola, Conselho de Administração e Conselho de Orientação, sem prejuízo de seus próprios órgãos de representação, delegação, seção sindical e associação dos alunos, e conselho de orientação dos estudos.

Por outro lado, reforçando a direção dos estudos, colocando em torno do diretor de ensino uma verdadeira equipe docente permanente, conforme havia sido firmemente recomendado pela Comissão de reforma. Essa equipe compreende, em torno do Diretor de ensino, atualmente elemento formado em Direito Público, três conselheiros, um para as matérias científicas e gerência moderna, o segundo um economista e o terceiro o conselheiro para idiomas.

\section{As missões secundárias da Escola}

No estado atual, a Escola tem uma missão principal que é a formação dos administradores gerais do Estado, mas ela tende a desenvolver seu papel em matéria de pesquisa aplicada à administração, terreno em que pode trazer, em decorrência da riqueza de informações concretas de que dispóe, uma contribuição muito apreciável.

Em compensação, a E.N.A. não tem qualquer missão direta no domínio da formação permanente ou do aperfeiçoamento dos funcionários. Em 
1945 foi criado e funcionou durante anos um Centro de Altos Estudos administrativos, cuja direção era confiada ao Diretor da Escola. Ele tinha por finalidade completar a formação necessária ao exercício das altas funções públicas. O Centro funcionou durante anos porém num contexto diferente das preocupações atuais em matéria de formação permanente.

A missão de formação permanente dos funcionários, dos quadros da administração, depende e deve depender da Diretoria Geral da Administração e da Função Pública, que é a única a ter uma visão de conjunto de todo o pessoal da administração e da função pública. Além disso, cada administração deve preocupar-se em organizar uma formação permanente para seus funcionários.

Contudo a E.N.A. se interessa pelos problemas de formação permanente e prestará seu concurso. Em especial no domínio da administração moderna, que se denomina gerência, ela decidiu associar-se a outras grandes escolas francesas, sobretudo às de natureza científica ou de preparação para os negócios, com vistas a criar um centro encarregado de definir as concepções nesse terreno, de auxiliar as escolas na busca dos professores e de estruturar os programas de aperfeiçoamento, cuja originalidade residiria em fazer refletirem juntos os funcionários e os quadros do setor privado.

Em seu domínio próprio de formação dos quadros gerais da administração do Estado e de sua represen- tação no exterior, a criação e depois a própria evolução da Escola, as reformas de que foi objeto, testemunham a importância, mas também a dificuldade, da gravidade desse problema para qualquer Estado. A esse respeito, a experiência adquirida e as reflexões feitas após mais de vinte e cinco anos autorizam um certo número de observações que serão apresentados à guisa de conclusão.

É preciso ser aqui absolutamente exato. Na realidade, a grande dificuldade, a única mesmo, por que passa de fato a Escola Nacional de Administração é a de que, por sua própria natureza, ela torna mais agudos para a administração problemas que se lhe colocariam de qualquer maneira, mesmo se a Escola não existisse e se outras fórmulas de recrutamento e de formação fossem adotadas.

Mas, depois de 25 anos, por inércia, por particularismos dos órgãos ou por espírito sindical de corporação, a administração não quer encarar esses problemas de frente, nem atacá-los vigorosamente: descompartimentação dos órgãos e das administrações; mobilidade real dos funcionários entre esses órgãos e especialmente entre Paris e as províncias, de conformidade com as necessidades de uma regionalização nascente; administração previsiva do pessoal, ao mesmo tempo qualitativa e quantitativa; política decidida de promoções internas, de conformidade com a justiça social e que o concurso para funcionários de ingresso na E.N.A., com suas 30 a 40 vagas por ano, não pode evidentemente resolver por si só; igual dignidade dos órgãos em lugar de uma estratificação injusta e nefasta. 
Alguns desses problemas se colocavam desde 1945 e os criadores da Escola estavam conscientes deles quando escreviam, como foi relembrado mais acima, que a criação da Escola era apenas parte de uma reforma administrativa de conjunto, que o país continua esperando com impaciência maior.

Os outros problemas surgiram depois, à medida em que, contrariamente ao espírito inicial, as administrações se compartimentavam e os órgãos se fechavam sobre si mesmos. Em 1964 foram tomadas medidas teoricamente boas, como por exemplo a reunificação dos quadros de administradores civis, como reação contra essas tendências, mas essa unidade, reforçada ainda em 1972, só existe nos textos e suas primeiras aplicações mal e timidamente começam a ser realizadas.

As gerações jovens são profundamente sensíveis a todos esses problemas e com justa razão, pois de sua solução depende a renovação da administração francesa. Esta pressupõe inicialmente uma modificação profunda do estado de espírito, permitindo ao mesmo tempo uma lúcida tomada de consciência e a vontade de proceder, de forma progressiva mas contínua, às modificações necessárias. Na verdade, nenhuma reforma administrativa é possível sem uma evolução profunda do estado de espírito e as modificações de estrutura de nada servem se esse estado de espírito, e o estado de costumes que ele acarreta, permanece inalterado.

A evolução da Escola Nacional de Administração, tal como foi reprodu- zida no presente artigo, permite extrair uma lição que devemos ter sempre presente quando pensamos em recrutamento e formação dos quadros superiores do Estado. Esta reflexão deve estar presente qualquer que seja o sistema e não se deveria esperar poder fugir aos problemas que vêm de ser recordados através dessa ou daquela fórmula, como muitos são tentados a fazer na França, quando se discute as dificuldades que enfrenta a E.N.A.

É preciso compreender-se bem que esta escola se encontra presa entre a Universidade e a Administração, em uma sociedade ela mesma em profunda transformação.

Pelo seu recrutamento, pelo menos de estudantes, que formam dois terços de seus efetivos, ela é tributária da primeira e, por suas saídas, ela depende estreitamente da segunda. Não se poderia portanto, sem faltar com a verdade dos fatos e com a justiça, imputar, somente à Escola as imperfeições e os males que se situam fora dela própria.

Quanto à administração, é dela e somente dela que depende a utilização inteligente dos jovens recrutados e formados com tanto cuidado, uma vez que atualmente tudo mostra que a administração francesa tem ainda de fazer imensos progressos para ter uma verdadeira política de emprego de seus elementos.

Nesses dois campos que não dependem de sua autoridade, a direção da Escola tem, sem dúvida, um papel a desempenhar, de discussão, de per- 
suasão e de colaboração, porém ela não pode sozinha resolver esses problemas.

Qualquer outra fórmula que não a Escola atual deveria resolver esses problemas. Em especial uma das críticas habitualmente feitas ao regime é o que se denomina o monopólio de recrutamento da E.N.A., fórmula aliás muito inexata por seu caráter absoluto: se é verdade que a Escola recruta para os postos iniciais dos quadros superiores da administração, existem outras vias de acesso a esses mesmos postos, senão a todos pelos menos aos mais numerosos deles: administradores civis, quadros municipais e relações exteriores especialmente, pela via da promoção interna que na França, infelizmente, é totalmente insuficiente sob 0 ponto de vista social, porque ela não é jamais considerada que como -o apên. dice de uma política de recrutamento ou de nomeação estabelecida em outras bases, as dos concursos.

Outras fórmulas freqüentemente invocadas - por exemplo, Escola de Estado Maior, recrutando apenas funcionários, ou Escola Nacional Superior de Administração - não resolvem quaisquer dos problemas que realmente se apresentam.

A fórmula da Escola Normal Superior de Administração, por exemplo, embora permitisse talvez abrir, tanto para o ensino como para a agregação, os concursos diretos de acesso aos diferentes órgãos e ministérios simultaneamente para os alunos da Escola dita normal superior de administração e para os jovelis provenientes das
Universidades ou da função pública, não teria por si própria papel algum na formaçáo propriamente dita dos fu. turos funcionários porque ela se limitaria a preparar concursos. E a criação de uma escola necessariamente onerosa não pode ser justificada por essa única função.

Todas as vantagens que, por outro lado, resultam para o Estado da orientação comum que dá a seus quadros os mais variados uma formação minis. trada ela mesma em comum, desapareceriam em detrimento da coesão futura da própria administração.

Se a dificuldade de reformar a administração francesa tornasse impos. sível, a longo prazo, a manutenção da forma atual da E.N.A., o regime que se poderia imaginar deveria de todo modo atender a duas condições: a) repousar sobre a idéia essencial de que um Estado moderno tem o maior interesse em ministrar, durante um período suficientemente longo, a todos seus funcionários superiores, enquanto ainda são jovens, uma formação em comum, pois esta é a garantia da coesão da administração e da unidade do Estado que, num mundo perturbado e em plena transformação, é mais do que nunca necessária; b) permitir resolver os problemas que se colocam à administração, quer ela queira ou não, e que não superaria modificando o sistema de recrutamento e de formação.

Mas o autor deste artigo não pensa que esta reforma da administração seja impossível; considera, ao contrário, que ela deve ser permanente. 


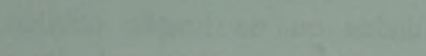

sudtar

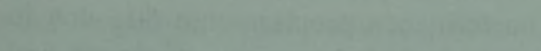

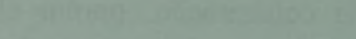

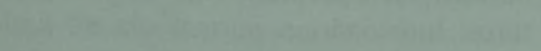

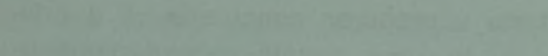

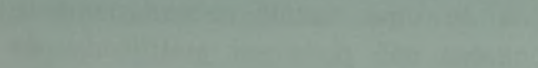

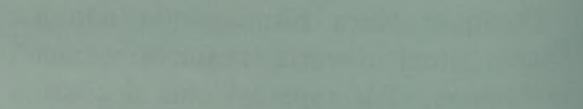

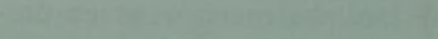

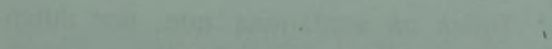

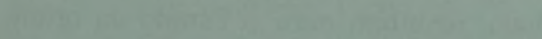

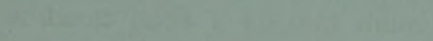

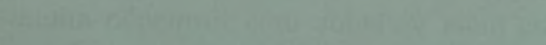

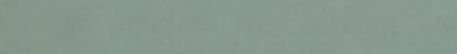

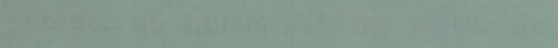

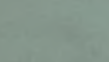



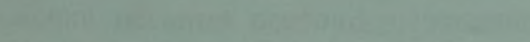

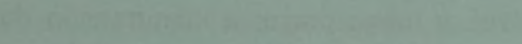

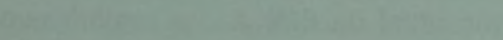

Whit

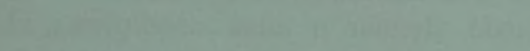

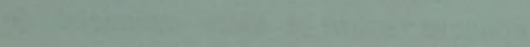

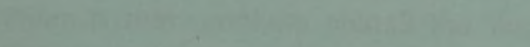

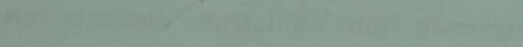

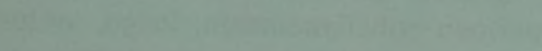

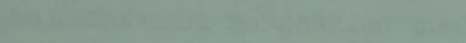

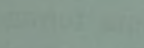



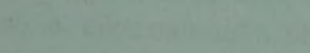

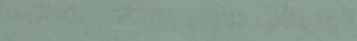

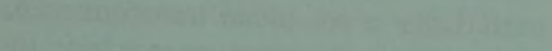

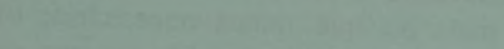

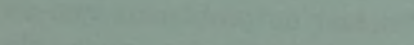

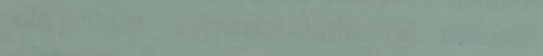

the

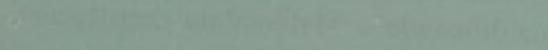

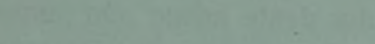

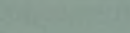

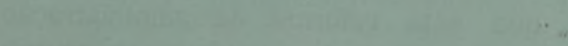

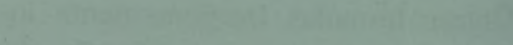

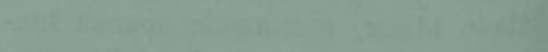

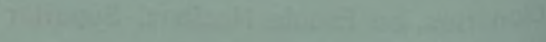

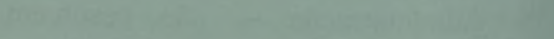

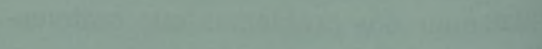

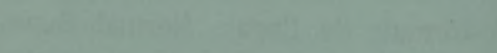



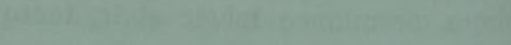
at



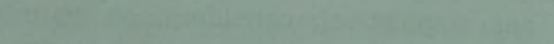

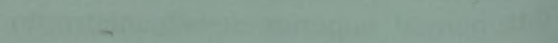

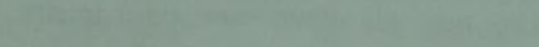

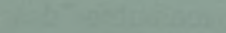

